\title{
Maurício de Nassau criou uma Sistemática Administrativa
}

\section{Luiz Pinto}

\author{
"Está capaz para se edificar nêle um grande império" — GABRIEL \\ SOARES DE SOUSA - Tratado Descritivo do Brasil.
}

$\mathrm{H}$ oUVE, na verdade, causas econômicas, sociais, políticas e culturais na administração que o conde João Maurício de Nassau inaugurou na faixa de terra brasileira, conquistada pela Holanda no século XVII. E foram tão evidentes essas causas, tornaram-se tão objetivos os seus atos de govêrno que, hoje, na frieza da exegese social, demonstram uma sistemática administrativa que merece esmiuçada, discutida e apontada aos estudiosos dos problemas brasileiros.

A origem das invasões batavas às terras brasileiras, primeiramente à Bahia (1624) e, mais tarde, a Pernambuco (1630), teve objeto indiscutivelmente econômico. É que, tangidos da Península Ibérica, no século XV, os judeus foram alojar-se na Holanda e criaram na república dos chamados Países Baixos um espirito comercial que se fêz notável. (1) A Holanda, separada da Espanha, após tremenda luta, não tardou em constituir-se numa forte potência naval, que deveria poder enfrentar as eventualidades de uma possível ação colonizadora. (2)

E tão densa se tornou a ação do judeu no comércio e na vida holandesa que o historiador luso, Oliveira MARTINs, acha que a Holanda se "constituíra numa companhia de piratas".

Guardando certo ódio à Península Ibérica, e mais ainda à Espanha do que a Portugal, os batavos queriam maior expansão, não admitindo que o mundo se tornasse num monopólio de lusos e espanhóis. E foi dentro dêsse pensamento, cultivando essa norma de ação que, logo nos primeiros quartéis do século XVII, fizeram nascer a célebre Companhia Privilegiada das Indias Orientais, instaurada em 1602. (3) Destinava-se essa emprêsa a atuar no Indostão, na África e Ilhas do Pacífico. (4) Os resultados dessa fundação foram compensadores. E, por isso, cheios de ânimo, os holandeses em 1621 organizaram outra companhia, da mesma natureza e parte da primeira, a que denominaram Companhias Privilegiadas das Índias Ocidentais. Essa visava

(1) Basílio de Magalhães - História do Brasil - Rio, 1943.

(2) Oliveira MARTINS - O Erasil e as colônias portuguêsas - Lisboa.

(3) Francisco Adolfo de Varnhagen - História Geral do Brasil - Rio, 1948.

(4) JOÃo RIIEIRO - História do Brasil, - Rio, 1914. 
explorar o Brasil, a terra cobiçada desde o descobrimento, desde o comércio do ibirapitanga, que os franceses levavam em quantidade. (5)

O Brasil, naqueles dias de 1624 e 1630, não tinha diretriz política, nem traço cultural próprio, nem rumo administrativo de influência homogênea. "Só uma coisa existia naquele Brasil, era um fanático amor à sua unidade geográfica, que se expressou na valentia, inteligência e argúcia de três raças que formaram a sua etnia: a branca, com Vidal de Negreiros; a preta, com Henrique Dias; a índia, com Felipe Camarão". (6)

Na época da conquista flamenga não era mais o pau brasil, então já superado, a melhor fonte de vida. Era a cana de açúcar que enchia as vistas dos invasores e compensava todos os sacrifícios para conquistá-la.

O príncipe Maurício de Nassau foi o consubstanciador da conquista holandesa. Promoveu a expansão territorial, assenhoreou-se de grande faixa de terra, cometeu alguns erros, de início, mas logo cedo aprumou-se e deu comêço a uma administração que foi, por todos os seus ângulos, um desadormecimento de energias criadoras. (7)

Não era de crer-se que os batavos pudessem obter maior fixação na faixa nordestina. As lutas religiosas, as emboscadas políticas, tanto de portuguêses como de brasileiros, traziam em constantes sobressaltos os ousados invasores.

Mas a chegada de Maurício, em 1637, foi uma garantia de unidade à conquista flamenga. Hábil, o príncipe de Nassau apercebeu-se da realidade ambiente, sentiu os choques de raças e religiōes e a sua primeira medida administrativa foi a de liberdade de crença, com que começara a desarmar ódios e conquistar gerais simpatias. (8) As letras, as artes, a construção da cidade do Recife começaram a merecer o melhor da sua atenção e esforços.

Os homens principais da terra logo se aproximaram de Nassau. A aversão geral foi desaparecendo e mudou-se afinal em reconhecida simpatia. (9)

A sua administração teve boa base, pois além dos problemas econômicos, como o caso dos engenhos e outros, vinha o aspecto jurídico, cuidado com as diretorias municipais, e o cultural, evidenciado com a presença no Recife de figuras do maior destaque em vários gêneros do conhecimento humanístico, por onde se sente que Nassau fôra um criador de civilizações.

Sabe-se da permanência em Pernambuco do célebre pintor A. Eckout, que nos deixou grandes telas. Além da pintura, da arquitetura, botânica, etc. também o realce das letras, onde atuaram algumas figuras de relêvo, entre elas o capelão Francisco Plante, autor de belos poemas. Como nos mostra Gilberto Freyre, ainda no Recife se viam Willen Piso, médico e sábio, o matemático Cralitz e o botânico Marcgrav, como ainda o cosmógrafo Ruiters .

Mas o que interessa na construção da sociologia administrativa do Brasil é conhecer a organização que se levou a efeito na administração da Nova Holanda, como ficou sendo chamada pelos batavos a faixa de terra de sua conquista colonizadora.

(5) Pedro Calmon - História do Brasil, $2 .^{\circ}$ volume - Rio.

(6) Luiz Pinto - Vidal de Negreiros - Rio, 1942.

(7) WATJEN - O Domínio Colonial holandês no Brasil - Rio, 1938.

(8) Francisco adolfo de Varnhagen - História das lutas - Lisboa, 1872.

(9) JoÃo RIBEIRO - História do Brasil - Rio, 1914. 
E bem certo que, pela falta de documentos, pelo desaparecimento das atas da Companhia e mesmo dos conselhos diretores, torna-se obscuro o período da vida holandesa, de 1630 a 1636 .

HERMAN WATJEN, autor que não cria heróis nem mártires, porque não se afasta da feição científica da história, dá-nos o depoimento que segue sôbre a organização político-administrativa da fase maurícia: "junto ao governador foi criado o "Colégio do Alto Conselho Secreto", composto de três diretores experimentados. Os seus membros eram de nomeação da Diretoria-Geral da W. I. C., mas só podiam tomar posse do cargo depois que os altos Poderes e o Príncipe Frederico Henrique de Orange houvesse manifestado a sua aprovação". (10)

Vê-se que havia um rígido regime de subordinação administrativa, que se caracterizava pelo fator econômico, através do poderio da Companhia, consubstanciado em poderosos Conselhos, aos quais cabia, além do mais, a fiscalização suprema dos negócios judiciários e financeiros da colônia e se distriBuíam por tôdas as capitanias conquistadas.

A administraçãc holandesa pode-se dizer que foi a administração do açúcar. O poderio dessa agricultura tomou tal vulto que um tratadista tem, sôbre ela, conceito palpitante, quando afirma: "Essse açúcar serve para regalo, para alimento e para remédio".

A sistemática administrativa que se nota na fase maurícia, no govêrno da Nova Holanda, se define, primeiro, pela liberdade de crença e culto, medida que implanta a paz entre tôdas as almas, sobressaltadas com a intrasigência dos primeiros Conselhos antes de Nassau; segundo, por não distinguir negros e brancos, o que veio desarmar velhas separações que quase sempre degeneravam em lutas e pânicos; terceiro, pelo amor à terra e fixação do homem ao campo, pelo estímulo aos engenhos de açúcar, que logo passaram a florescer com a sua produção multiplicada; quarto, pela compreensão humana, gôsto pela arte, pela botânica, pela geografia, pela cultura em geral; e quinto, pelo espírito objetivo, realizador, colonizador por excelência. (11)

Apreciando a atuação do Príncipe João Maurício de Nassau, na administração, durante o seu período de govêrno (1637 - 1644), diz Jônatas Serrano: "Não era Maurício de Nassau um vulgar administrador. Idealista e liberal, concebeu um grandioso plano de organização, que chegou a alarmar a Companhia, receosa de que êle fundasse na América uma monarquia particular. Assim que chegou ao Recife, proclamou a liberdade religiosa e a libertação dos negros"... criou uma milícia dos naturais da terra". (12)

A administração de Maurício de Nassau foi tôda moldada em atos os mais sensatos de organizações de trabalho, de sistemática, criando concepções novas num meio inculto, nativo mesmo, onde só havia o instinto de conservação. Dosado de grande espírito prático, as suas decisões eram firmes, mas levadas a efeito com prudência e habilidade. (13)

(10) Hermann Watjen -- O Domínio Colonial Holandês no Brasil - Rio, 1938.

(11) GASPAR BARLÉU - O Brasil sob o conde João Mauticio de Nassau - ed. do

Ministério da Educação -- Rio.

(12) Jônatas Serrano - História do Brasil - Rio, 1931.

(13) JÔnatas SERRANo, ob. cit. 
Maurício não era um simples soldado, um simples homem de guerra, pois possuía excelentes qualidades de homem de estado. (14)

Sabe-se, assim, que o seu rumo administrativo teria de ser amalgamado nas diretivas da companhia de comércio que determinou a conquista. Mas, dada a sua cultura e bom senso, o seu alcance social, a experiência dos fracassos administrativos do período de 1630 a 1636 , - antes, portanto, da sua gestão, Maurício foi aos poucos criando novos epigramas administrativos, e, com tanta fôrça, que se pode notar fàcilmente, estudando os seus atos, um caminho certo, que não é produto de reflexos europeus, pois ainda estavam longe os dias do século XVIII, do enciclopedismo, senão o produto do raciocínio, da lógica, da razão, filtrado em métodos liberais intuitivos e que eram aconselhados à consubstanciação de tão arriscada conquista. (15)

Naqueles dias, que marcaram quase a metade do século XVII, Maurício estabilizou um regime político-administrativo que, se não fôra as lutas européias, as reviravoltas da política holandesa; se a inveja, o mêdo e conveniências não tivessem determinado a saída do príncipe; se Nassau houvesse continuado à frente da Nova Holanda, sediada no Recife, talvez outros rumos tivessem sido traçados à história do Brasil. (16)

- Mas, dêsse ou daquele modo, o que se não nega é que nos seus sete anos de govêrno João Maurício de Nassau construiu uma rota administrativa à parte do Brasil conquistada pela Holanda, servindo-se para isto não sòmente do fator econômico, que o açúcar representava fortemente, senão também da cultura humanística, do bem-estar social e da harmonia política. Daí poderse afirmar que aquêle período administrativo é um travejamento à sociologia administrativa do Brasil, pelos múltiplos aspectos que apresenta, sendo, depois de Duarte Coelho o desbravador da conquista lusa em Pernambuco, o elemento que sintetiza o sentido social, portanto, o sentido humano da administração.

\section{SUMMARY}

1. The administration of Nassau in Brazil (Dutch invasion and occupation of a Northeastern section of the Brazilian territory in the 17th century) deserves close scrutiny.

2. The causes of the Dutch invasion discussed. Origin and development of the LowCountries. The Jewish influence and Dutch trade. The rivalry between Spain and the LowCountries. The East India Company and the West India Company.

3. Nassau's administrative policies in Brazil. The achievements in the economic, literary, scientific and artistic fields. The legal structure of administration. The supervision of the West India Company through the High Secret Council of three members. The sugar industry as the economic basis of Dutch administration.

4. Specific aspects of Nassau's administration: the freedom of religion; the absence of racial prejudices; the fixation of rural populations in their environment through the encouragement of the sugar-cane plantations; the fostering of humanism and the protection of the sciences, arts and letters; the emphasis placed upon objetive, practical endeavors.

5. Appreciation of Nassau as a stateman: his talents and firmness of purpose allied to common sense, tact and prudence. His achievements superseded the designs of the West India Company and revealed his high powers of reasoning at the service of the administrative problems of a peculiar millieu. Had not Nassau been sent back to Europe and a diffee rent direction might have been given to the history of Brazil.

(14) Rocha Pомво - História do Brasil - Rio, 1952 (6.a edição).

(15) ROBERT SOUTHEY - História do Brasil -- Bahia, 1949.

(16) LuIz PINTo - Vidal de Negreiros - Rio, 1942. 